\title{
A population-based case-control study of diet and melanoma risk in northern Italy
}

\author{
Marco Vinceti ${ }^{1, *}$, Giovanni Pellacani ${ }^{2}$, Carlotta Malagoli ${ }^{3}$, Stefania Bassissi ${ }^{2}$, \\ Sabina Sieri ${ }^{3}$, Francesca Bonvicini ${ }^{1}$, Vittorio Krogh ${ }^{3}$ and Stefania Seidenari ${ }^{2}$ \\ 'Department of Public Health Sciences University of Modena and Reggio Emilia, Via Campi 287, I-41 100 Modena, \\ Italy: ${ }^{2}$ Department of Dermatology, University of Modena and Reggio Emilia, Via Del Pozzo 71, I-4 1100 Modena, \\ Italy: ${ }^{3}$ Department of Epidemiology, National Cancer Institute, Via Venezian 1, I-20133 Milan, Italy
}

Submitted 20 October 2004: Accepted 10 May 2005

\begin{abstract}
Objective: We aimed at examining the association between dietary constituents and risk of cutaneous melanoma.

Design: In an area of northern Italy we recruited 59 newly diagnosed melanoma patients and 59 age- and sex-matched population controls, to whom we administered a validated semi-quantitative food-frequency questionnaire.

Results: We found an excess risk of melanoma in subjects with a higher energyadjusted intake of total polyunsaturated fatty acids and, in particular, of linoleic acid (relative risk $=2.16$ for intake in the highest tertile compared with the lowest tertile, $P$ for linear trend $=0.061$ ). Conversely, disease risk was inversely associated with the consumption of soluble carbohydrates (relative risk $=0.34$ for intake in the upper vs. the lowest tertile adjusting for total energy intake, $P$ for linear trend $=0.046$ ). No other dietary factors, including alcohol, vitamins and trace elements, correlated with melanoma risk. The association of melanoma risk with linoleic acid and soluble carbohydrates intakes was further strengthened in multivariate analysis, and when analysis was limited to females.

Conclusions: Overall, these results indicate that an excess energy-adjusted intake of linoleic acid and a lower consumption of soluble carbohydrates may increase melanoma risk.
\end{abstract}

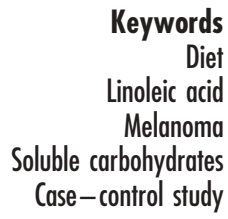

A recent report from England on trends in cancer occurrence between 1991 and 2000 classifies melanoma as having the highest increase in incidence among all sitespecific neoplasms ${ }^{1}$. The incidence of melanoma has increased generally in western European countries during the last few years, and early detection owing to screening does not appear as the only explanation for this $\mathrm{fact}^{2}$. This points to the role of environmental risk factors in increasing melanoma incidence, but the exact nature of these factors, apart from ultraviolet exposure, is still unclear ${ }^{3}$. Diet has long been suspected of playing a role in favouring melanoma occurrence, and new interest in this issue has recently been raised by two large hospital-based casecontrol studies ${ }^{4,5}$, although the results of the few investigations carried out so far have yielded inconsistent results $^{3,6}$. To further explore the possible relationship between dietary factors and melanoma risk, we carried out a population-based case-control study in an Italian region.

\section{Methods}

We carried out a population-based case-control study to investigate the possible relationship between environmental factors and risk of cutaneous melanoma in the population from Modena Province, an area in northern Italy with approximately 650000 inhabitants $^{7}$. We recruited for a period of three consecutive years all the patients newly diagnosed with cutaneous melanoma attending the Dermatologic Clinic of Modena University Hospital, which is the only centre for diagnosis, therapy and follow-up of the disease within the province. Inclusion criteria were residence in Modena Province and a histologically based recent diagnosis of cutaneous melanoma without clinical evidence of metastasis. Fifty-nine out of the 82 patients (72.0\%) eligible to participate in the study accepted to do so.

Subsequently, we randomly selected a resident of Modena Province, sex- and age-matched ( \pm 5 years) to each patient. This was carried out by using the database for all Modena residents available at the Modena Local Health Authority. Eligible controls were contacted by telephone were enrolled in the study after having given their informed consent to the protocol and aims of the study. When a control subject could not be enrolled, another resident age- and sex-matched to the patient was contacted and invited to participate. 
Table 1 Crude and energy-adjusted relative risk of melanoma according to daily intake of dietary factors, case-control study on environmental determinants of cutaneous melanoma in Modena Province, northern Italy

\begin{tabular}{|c|c|c|c|c|c|}
\hline \multirow[b]{2}{*}{ Factor } & & \multicolumn{3}{|c|}{ Relative risk ( $95 \%$ confidence interval) } & \multirow{2}{*}{$\begin{array}{l}P \text { for linear } \\
\text { trend }\end{array}$} \\
\hline & & $I^{*}$ & II & III & \\
\hline \multirow{3}{*}{ Total proteins } & Crude & 1.00 & $1.33(0.46-3.84)$ & $0.50(0.15-1.66)$ & 0.514 \\
\hline & Energy-adjusted & 1.00 & $0.54(0.10-3.01)$ & $0.83(0.14-4.71)$ & 0.979 \\
\hline & Tertile cut-off $(\mathrm{g})$ & $<74.138$ & $\geq 74.138-<96.616$ & $\geq 96.616$ & \\
\hline \multirow[t]{3}{*}{ Animal proteins } & Crude & 1.00 & $0.87(0.32-2.41)$ & $0.62(0.20-1.91)$ & 0.477 \\
\hline & Energy-adjusted & 1.00 & $0.57(0.17-1.9)$ & $0.86(0.21-3.55)$ & 0.803 \\
\hline & Tertile cut-off (g) & $<49.383$ & $\geq 49.383-<70.429$ & $\geq 70.429$ & \\
\hline \multirow[t]{3}{*}{ Vegetable proteins } & Crude & 1.00 & $1.83(0.68-4.96)$ & $0.60(0.14-2.51)$ & 0.793 \\
\hline & Energy-adjusted & 1.00 & $1.60(0.50-5.07)$ & $0.89(0.05-14.47)$ & 0.549 \\
\hline & Tertile cut-off (g) & $<19.256$ & $\geq 19.256-<30.911$ & $\geq 30.911$ & \\
\hline \multirow{3}{*}{ Total fat } & Crude & 1.00 & $1.67(0.61-4.59)$ & $0.60(0.14-2.51)$ & 0.799 \\
\hline & Energy-adjusted & 1.00 & $1.06(0.18-6.20)$ & $1.21(0.09-15.28)$ & 0.369 \\
\hline & Tertile cut-off (g) & $<68.722$ & $\geq 68.722-<89.503$ & $\geq 89.503$ & \\
\hline \multirow[t]{3}{*}{ Animal fat } & Crude & 1.00 & $0.87(0.32-2.41)$ & $0.56(0.19-1.66)$ & 0.446 \\
\hline & Energy-adjusted & 1.00 & $0.57(0.17-1.89)$ & $0.80(0.17-3.72)$ & 0.752 \\
\hline & Tertile cut-off (g) & $<39.099$ & $\geq 39.099-<54.773$ & $\geq 54.773$ & \\
\hline \multirow{3}{*}{ Vegetable fat } & Crude & 1.00 & $2.33(0.60-9.02)$ & $0.83(0.25-2.73)$ & 0.623 \\
\hline & Energy-adjusted & 1.00 & $2.87(0.63-13.18)$ & $1.01(0.20-5.04)$ & 0.215 \\
\hline & Tertile cut-off (g) & $<24.586$ & $\geq 24.586-<37.775$ & $\geq 37.775$ & \\
\hline \multirow{3}{*}{ Total saturated fatty acids } & Crude & 1.00 & $1.25(0.49-3.17)$ & $0.57(0.17-1.95)$ & 0.488 \\
\hline & Energy-adjusted & 1.00 & $0.66(0.17-2.53)$ & $0.92(0.12-7.28)$ & 0.890 \\
\hline & Tertile cut-off (g) & $<23.465$ & $\geq 23.465-<33.606$ & $\geq 33.606$ & \\
\hline \multirow[t]{3}{*}{ Oleic acid } & Crude & 1.00 & $9.00(1.14-71.04)$ & $1.00(0.25-3.40)$ & 0.962 \\
\hline & Energy-adjusted & 1.00 & $43.07(1.96-944.69)$ & $5.01(0.44-57.13)$ & 0.355 \\
\hline & Tertile cut-off (g) & $<27.095$ & $\geq 27.095-<40.143$ & $\geq 40.143$ & \\
\hline \multirow[t]{3}{*}{ Total monounsaturated fatty acids } & Crude & 1.00 & $8.00(1.00-63.96)$ & $1.25(0.34-4.65)$ & 0.927 \\
\hline & Energy-adjusted & 1.00 & $30.51(1.45-643.90)$ & $5.33(0.56-50.73)$ & 0.377 \\
\hline & Tertile cut-off (g) & $<29.338$ & $\geq 29.338-<42.587$ & $\geq 42.587$ & \\
\hline \multirow[t]{3}{*}{ Linoleic acid } & Crude & 1.00 & $0.78(0.29-2.09)$ & $1.00(0.32-3.10)$ & 0.290 \\
\hline & Energy-adjusted & 1.00 & $0.35(0.08-1.54)$ & $2.16(0.40-11.72)$ & 0.061 \\
\hline & Tertile cut-off (g) & $<6.976$ & $\geq 6.976-<8.811$ & $\geq 8.811$ & \\
\hline Linolenic acid & Crude & 1.00 & $1.25(0.49-3.17)$ & $0.43(0.11-1.66)$ & 0.859 \\
\hline & Energy-adjusted & 1.00 & $0.59(0.16-2.24)$ & $0.97(0.14-6.53)$ & 0.459 \\
\hline & Tertile cut-off $(\mathrm{g})$ & $<1.001$ & $\geq 1.001-<1.296$ & $\geq 1.296$ & \\
\hline Other polyunsaturated fatty acids & Crude & 1.00 & $4.33(1.23-15.21)$ & $0.67(0.19-2.36)$ & 0.288 \\
\hline & Energy-adjusted & 1.00 & $7.13(1.49-34.06)$ & $0.73(0.16-3.29)$ & 0.408 \\
\hline & Tertile cut-off (g) & $<0.411$ & $\geq 0.411-<0.799$ & $\geq 0.799$ & \\
\hline Total polyunsaturated fatty acids & Crude & 1.00 & $1.14(0.41-3.15)$ & $1.00(0.32-3.10)$ & 0.399 \\
\hline & Energy-adjusted & 1.00 & $0.55(0.13-2.33)$ & $2.62(0.45-15.35)$ & 0.080 \\
\hline & Tertile cut-off $(\mathrm{g})$ & $<8.407$ & $\geq 8.407-<10.830$ & $\geq 10.830$ & \\
\hline Cholesterol & Crude & 1.00 & $0.29(0.06-1.37)$ & $0.50(0.17-1.46)$ & 0.210 \\
\hline & Energy-adjusted & 1.00 & $0.18(0.03-0.96)$ & $0.50(0.12-2.12)$ & 0.252 \\
\hline & Tertile cut-off (mg) & $<289.751$ & $\geq 289.751-<402.895$ & $\geq 402.895$ & \\
\hline Available carbohydrates & Crude & 1.00 & $1.80(0.60-5.37)$ & $0.50(0.12-2.00)$ & 0.346 \\
\hline & Energy-adjusted & 1.00 & $1.82(0.43-7.62)$ & $0.42(0.03-5.90)$ & 0.468 \\
\hline & Tertile cut-off (g) & $<195.850$ & $\geq 195.850-<291.882$ & $\geq 291.882$ & \\
\hline Starch & Crude & 1.00 & $1.67(0.61-4.59)$ & $0.83(0.25-2.73)$ & 0.962 \\
\hline & Energy-adjusted & 1.00 & $1.55(0.45-5.28)$ & $6.76(0.57-80.02)$ & 0.367 \\
\hline & Tertile cut-off $(\mathrm{g})$ & $<97.738$ & $\geq 97.738-<165.190$ & $\geq 165.190$ & \\
\hline Soluble carbohydrates & Crude & 1.00 & $0.75(0.26-2.16)$ & $0.57(0.17-1.95)$ & 0.055 \\
\hline & Energy-adjusted & 1.00 & $0.73(0.23-2.27)$ & $0.34(0.07-1.73)$ & 0.046 \\
\hline & Tertile cut-off (g) & $<86.256$ & $\geq 86.256-<114.814$ & $\geq 114.814$ & \\
\hline Dietary fibre & Crude & 1.00 & $1.75(0.51-5.98)$ & $2.00(0.50-8.00)$ & 0.560 \\
\hline & Energy-adjusted & 1.00 & $2.24(0.55-9.07)$ & $2.14(0.31-14.77)$ & 0.905 \\
\hline & Tertile cut-off (g) & $<14.457$ & $\geq 14.457-<20.276$ & $\geq 20.276$ & \\
\hline Alcohol & Crude & 1.00 & $1.67(0.61-4.59)$ & $0.50(0.12-2.00)$ & 0.807 \\
\hline & Energy-adjusted & 1.00 & $1.86(0.64-5.42)$ & $0.97(0.17-5.50)$ & 0.978 \\
\hline & Tertile cut-off $(\mathrm{g})$ & $<1.625$ & $\geq 1.625-<23.248$ & $\geq 23.248$ & \\
\hline Energy & Crude & 1.00 & $1.67(0.61-4.59)$ & $0.43(0.11-1.66)$ & 0.482 \\
\hline & Tertile cut-off (kcal) & $<1766.41$ & $\geq 1766.41-<2365.391$ & $\geq 2365.391$ & \\
\hline Iron & Crude & 1.00 & $0.67(0.24-1.87)$ & $0.83(0.25-2.73)$ & 0.380 \\
\hline & Energy-adjusted & 1.00 & $0.16(0.02-1.07)$ & $1.45(0.19-11.3)$ & 0.548 \\
\hline & Tertile cut-off (mg) & $<11.666$ & $\geq 11.666-<14.934$ & $\geq 14.934$ & \\
\hline Calcium & Crude & 1.00 & $1.60(0.52-4.89)$ & $1.00(0.32-3.10)$ & 0.384 \\
\hline & Energy-adjusted & 1.00 & $1.89(0.50-7.12)$ & $0.81(0.14-4.73)$ & 0.604 \\
\hline & Tertile cut-off (mg) & $<757.927$ & $\geq 754.927-<1057.486$ & $\geq 1057.486$ & \\
\hline
\end{tabular}


Table 1. Continued

\begin{tabular}{|c|c|c|c|c|c|}
\hline \multirow[b]{2}{*}{ Factor } & & \multicolumn{3}{|c|}{ Relative risk (95\% confidence interval) } & \multirow{2}{*}{$\begin{array}{l}P \text { for linear } \\
\text { trend }\end{array}$} \\
\hline & & $I^{*}$ & II & III & \\
\hline \multirow[t]{3}{*}{ Sodium } & Crude & 1.00 & $0.78(0.29-2.09)$ & $1.20(0.37-3.93)$ & 0.979 \\
\hline & Energy-adjusted & 1.00 & $0.63(0.17-2.36)$ & $5.88(0.48-72.74)$ & 0.335 \\
\hline & Tertile cut-off (mg) & $<1796.629$ & $\geq 1796.629-<2518.013$ & $\geq 2518.013$ & \\
\hline \multirow[t]{3}{*}{ Potassium } & Crude & 1.00 & $1.14(0.41-3.15)$ & $1.50(0.42-5.31)$ & 0.628 \\
\hline & Energy-adjusted & 1.00 & $1.52(0.40-5.83)$ & $3.43(0.42-27.96)$ & 0.873 \\
\hline & Tertile cut-off (mg) & $<2642.938$ & $\geq 2642.938-<3370.434$ & $\geq 3370.434$ & \\
\hline \multirow[t]{3}{*}{ Phosphorus } & Crude & 1.00 & $1.00(0.37-2.66)$ & $0.40(0.12-1.27)$ & 0.325 \\
\hline & Energy-adjusted & 1.00 & $1.19(0.27-1.28)$ & $0.42(0.71-2.44)$ & 0.392 \\
\hline & Tertile cut-off (mg) & $<1192.072$ & $\geq 1192.072-<1601.103$ & $\geq 1601.103$ & \\
\hline \multirow[t]{3}{*}{ Zinc } & Crude & 1.00 & $1.80(0.60-5.37)$ & $0.67(0.19-2.36)$ & 0.491 \\
\hline & Energy-adjusted & 1.00 & $1.60(0.28-9.10)$ & $1.57(0.21-11.71)$ & 0.895 \\
\hline & Tertile cut-off (mg) & $<9.797$ & $\geq 9.797-<13.560$ & $\geq 13.560$ & \\
\hline \multirow[t]{3}{*}{ Thiamine } & Crude & 1.00 & $0.78(0.29-2.09)$ & $0.71(0.23-2.25)$ & 0.253 \\
\hline & Energy-adjusted & 1.00 & $0.46(0.12-1.73)$ & $0.62(0.11-3.57)$ & 0.308 \\
\hline & Tertile cut-off (mg) & $<0.916$ & $\geq 0.916-<1.158$ & $\geq 1.158$ & \\
\hline \multirow[t]{3}{*}{ Riboflavin } & Crude & 1.00 & $1.43(0.54-3.75)$ & $0.50(0.12-2.00)$ & 0.424 \\
\hline & Energy-adjusted & 1.00 & $1.17(0.34-4.01)$ & $0.84(0.13-5.37)$ & 0.681 \\
\hline & Tertile cut-off (mg) & $<1.231$ & $\geq 1.231-<1.590$ & $\geq 1.590$ & \\
\hline \multirow[t]{3}{*}{ Niacin } & Crude & 1.00 & $1.00(0.35-2.85)$ & $0.50(0.15-1.66)$ & 0.469 \\
\hline & Energy-adjusted & 1.00 & $0.45(0.10-1.95)$ & $0.31(0.05-1.93)$ & 0.799 \\
\hline & Tertile cut-off (mg) & $<15.516$ & $\geq 15.516-<20.024$ & $\geq 20.024$ & \\
\hline \multirow[t]{3}{*}{ Vitamin C } & Crude & 1.00 & $1.75(1.51-5.98)$ & $0.60(0.14-2.51)$ & 0.401 \\
\hline & Energy-adjusted & 1.00 & $1.77(0.51-6.15)$ & $0.71(0.13-4.03)$ & 0.553 \\
\hline & Tertile cut-off (mg) & $<85.739$ & $\geq 85.739-<105.794$ & $\geq 105.794$ & \\
\hline \multirow[t]{3}{*}{ Vitamin $\mathrm{B}_{6}$} & Crude & 1.00 & $0.37(0.10-1.41)$ & $1.33(0.46-3.84)$ & 0.590 \\
\hline & Energy-adjusted & 1.00 & $0.26(0.05-1.35)$ & $1.82(0.42-7.93)$ & 0.930 \\
\hline & Tertile cut-off (mg) & $<1.545$ & $\geq 1.545-<1.950$ & $\geq 1.950$ & \\
\hline \multirow[t]{3}{*}{ Folic acid } & Crude & 1.00 & $1.33(0.30-5.96)$ & $1.25(0.34-4.65)$ & 0.578 \\
\hline & Energy-adjusted & 1.00 & $1.84(0.27-12.29)$ & $1.25(0.18-8.60)$ & 0.992 \\
\hline & Tertile cut-off $(\mu \mathrm{g})$ & $<198.658$ & $\geq 198.658-<250.708$ & $\geq 250.708$ & \\
\hline \multirow{3}{*}{ Retinol equivalents } & Crude & 1.00 & $0.86(0.29-2.55)$ & $0.60(0.14-2.51)$ & 0.261 \\
\hline & Energy-adjusted & 1.00 & $0.76(0.21-2.81)$ & $0.64(0.14-2.95)$ & 0.349 \\
\hline & Tertile cut-off $(\mu \mathrm{g})$ & $<612.444$ & $\geq 612.444-<943.917$ & $\geq 943.917$ & \\
\hline \multirow[t]{3}{*}{ Retinol } & Crude & 1.00 & $0.67(0.24-1.87)$ & $1.00(0.25-4.00)$ & 0.229 \\
\hline & Energy-adjusted & 1.00 & $0.38(0.10-1.48)$ & $1.94(0.33-11.54)$ & 0.288 \\
\hline & Tertile cut-off $(\mu \mathrm{g})$ & $<246.16$ & $\geq 246.16-<428.833$ & $\geq 428.833$ & \\
\hline \multirow[t]{3}{*}{$\beta$-Carotene } & Crude & 1.00 & $2.00(0.60-6.64)$ & $1.50(0.42-5.31)$ & 0.844 \\
\hline & Energy-adjusted & 1.00 & $2.50(0.67-9.28)$ & $1.60(0.42-6.12)$ & 0.981 \\
\hline & Tertile cut-off $(\mu \mathrm{g})$ & $<1747.094$ & $\geq 1747.094-<3012.109$ & $\geq 3012.109$ & \\
\hline \multirow{3}{*}{ Vitamin E } & Crude & 1.00 & $1.37(0.55-3.42)$ & $1.20(0.37-3.93)$ & 0.484 \\
\hline & Energy-adjusted & 1.00 & $1.57(0.53-4.59)$ & $1.16(0.26-5.07)$ & 0.125 \\
\hline & Tertile cut-off (mg) & $<6.410$ & $\geq 6.410-<8.174$ & $\geq 8.174$ & \\
\hline \multirow[t]{3}{*}{ Vitamin D } & Crude & 1.00 & $0.86(0.29-2.55)$ & $0.78(0.29-2.09)$ & 0.247 \\
\hline & Energy-adjusted & 1.00 & $0.61(0.17-2.10)$ & $0.76(0.23-2.50)$ & 0.350 \\
\hline & Tertile cut-off $(\mu \mathrm{g})$ & $<2.039$ & $\geq 2.039-<2.940$ & $\geq 2.940$ & \\
\hline
\end{tabular}

* Lowest tertile.

The study protocol included a dermatological examination, administration of questionnaires on anamnestic data, diet and lifestyle habits, as well as the sampling of blood and toenails. Among the anamnestic data we collected, we paid particular attention to the overall history of sun exposure by asking information about estimated periods of the day and of the year spent in sunshine during the subject's lifetime, visits to tropical countries, history of any sunburn and of solar lentigines, and use of sunscreen. We also investigated the possible use of sunlamps and the phototype of the subject.

The dietary questionnaire was developed by epidemiologists from the Milan National Cancer Institute within the framework of the European Prospective Investigation on
Cancer and Nutrition (EPIC) $)^{8}$ and specifically designed for different Italian areas, such as Nord-Central Italy for the version adopted in the present study? ${ }^{9}$. It was a selfadministered, semi-quantitative food-frequency questionnaire divided into 14 sections: pasta and rice, soup, meat excluding cured meats, fish, raw vegetables, cooked vegetables, eggs, sandwiches, salami and other cured meat, cheese, fruit, bread and wine, milk/coffee/cakes, herbs and spices. The questionnaire included 248 questions on frequency (per day, month or year) of consumption of 188 food items. The quantity of each food consumed was assessed by selecting an image of a food portion using the 17 sets of pictures indicating small, medium and large portion sizes or slight modification of 
these quantities. Images of glasses and cups of different sizes were also used to estimate wine and milk consumption, and the type of fats used as condiments for some foods or if added after cooking was assessed. Cooking procedures were taken into consideration.

After compilation and collection, the questionnaires were read by expert personnel and computerised using an optical reader and software developed at the National Cancer Institute. In this process possible inconsistencies between 'linked' replies were checked (for example, details on cooking methods for salmon were not acceptable if no consumption of salmon was acknowledged). The software allowed for the calculation of consumption frequency and daily quantities of each food item, as well as the intake of dietary factors using the Italian Food Composition Tables for Epidemiologic Studies as the reference database ${ }^{10}$.

We computed odds ratios of melanoma as an estimate of relative risk (RR) according to categories of dietary factor intake, using a matched analysis based on bivariate and multivariate conditional logistic regression models. We divided the subjects according to tertile cut-offs of dietary factors, based on distribution in referents; for genderspecific analyses, we used the median as cut-off for OR calculation. To compute $P$-values for linear trends we entered into the model intakes of dietary factors as continuous variables. Adjustment for energy in multivariate analysis was performed by entering overall energy intake as a covariate in the model; for selected nutrients showing in this analysis an abnormally high RR or a tendency towards an association with melanoma risk, we also repeated the analyses by adjusting for energy intake using the residual method ${ }^{11}$. We fitted a cubic natural spline regression to evaluate the continuous relationship with melanoma risk of the two dietary factors more strongly associated with disease itself in the conditional logistic regression model, simultaneously adjusting for intake of the other dietary factor. To examine the relationship between age and intake of selected factors and total energy, we calculated the Spearman rank correlation coefficient.

\section{Results}

In total, 59 patients (28 males and 31 females, mean age 58.1 and 53.9 years, respectively) and 59 age- and sexmatched referents were included in the study. In Table 1 we report the RR of melanoma in the whole study population according to tertile distribution of the dietary factors, with and without adjustment for total energy intake. We found little evidence of an association with the majority of dietary constituents, with three exceptions: an excess risk associated with higher energy-adjusted intake of polyunsaturated fatty acids (PUFA) ( $P$ for linear trend $=0.080)$ and linoleic acid alone $(P$ trend $=0.061)$,
Table 2 Multivariate analysis of melanoma risk* according to intake of linoleic acid and soluble carbohydrates, case-control study on environmental determinants of cutaneous melanoma, Modena Province, northern Italy

\begin{tabular}{lccc}
\hline & \multicolumn{2}{c}{ Category } & $\begin{array}{c}P \text { for linear } \\
\text { trend }\end{array}$ \\
\cline { 2 - 3 } Dietary factor & It & II & 0.054 \\
\hline Linoleic acid & 1.00 & $1.59(0.61-4.13)$ & 0.017 \\
Soluble carbohydrates & 1.00 & $0.48(0.20-1.12)$ & 0 \\
\hline
\end{tabular}

* Relative risk of melanoma (95\% confidence interval) using conditional logistic regression and adjusting for the remaining dietary factor.

†Referent category (average nutrient intake below the median as calculated in controls).

and, in both the energy-adjusted and unadjusted analyses, a lower risk in subjects characterised by a higher intake of soluble carbohydrates $(P$ trend $=0.046)$. Total energy intake was not associated with risk of the disease. We also found a high risk of melanoma in subjects belonging to the middle tertile of intake for oleic acid and for total monounsaturated fatty acids, but the risks in the highest tertile and the trend analysis did not suggest an association between high intake of these dietary factors and disease risk.

When we entered in a multivariate model the two dietary factors most strongly associated with melanoma risk, linoleic acid and soluble carbohydrates, a stronger effect of these variables on melanoma risk than that detected in the bivariate analyses emerged (Table 2). In cubic spline multivariate regression analysis, risk increased smoothly at higher linoleic acid intake, particularly for low and high levels of this dietary factor, whilst there was little evidence of an association at intermediate levels of intake (Fig. 1). Concerning consumption of soluble carbohydrates, we detected a strong inverse linear relationship with disease risk only at the highest levels of intake (Fig. 2).

We repeated data analysis after stratification for gender, calculating the unadjusted and adjusted RR of melanoma

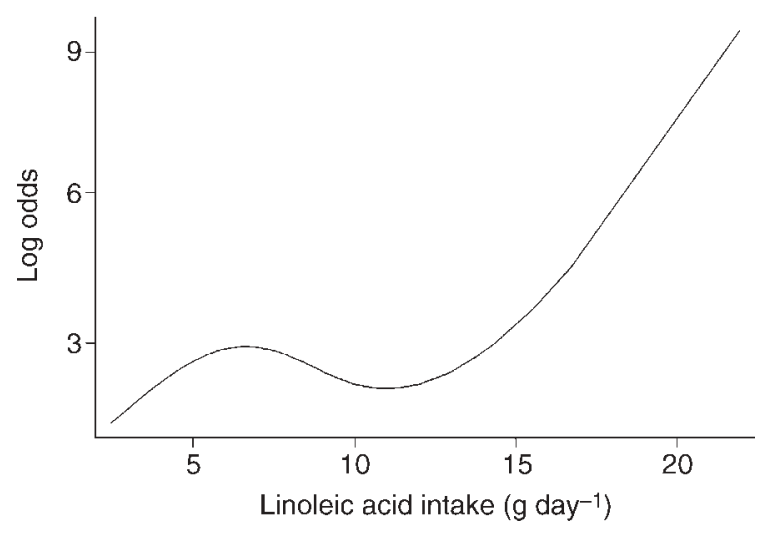

Fig. 1 Log odds of being a case at increasing intake of linoleic acid among population referents and patients with cutaneous melanoma, Modena, Italy (natural cubic spline regression adjusting for intake of soluble carbohydrates) 


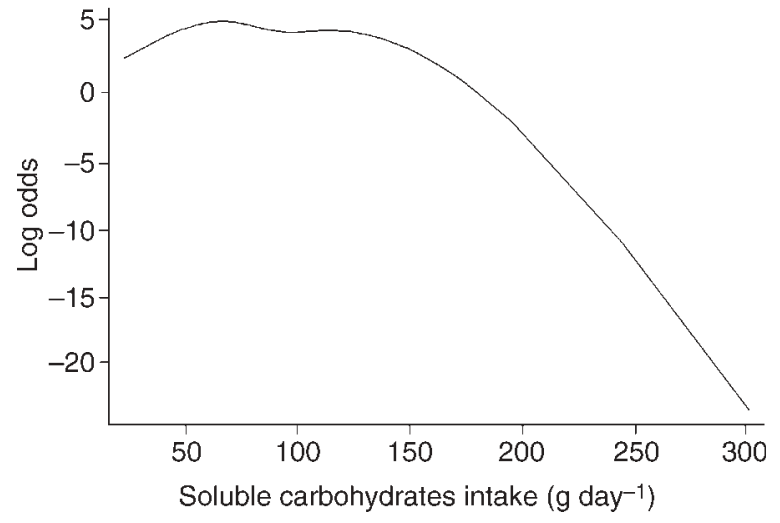

Fig. 2 Log odds of being a case at increasing intake of soluble carbohydrates among population referents and patients with cutaneous melanoma, Modena, Italy (natural cubic spline regression adjusting for linoleic acid intake)

associated with intake of linoleic acid and soluble carbohydrates equal or above the median value (Table 3). In multivariate analysis adjusting for energy and the other dietary factor, we observed in females a tendency towards excess risk in subjects having a higher intake of linoleic acid and a lower consumption of soluble carbohydrates. In males, despite RRs being generally comparable to estimates obtained in females, estimates were statistically very unstable. Inclusion in the analysis of factors such as body mass index, smoking, education, family history, indicators of overall sun exposure and history of sunburn, phototype and number of atypical nevi, or using the residual method for total energy intake adjustment, or repeating the analyses after stratification for age ( $\leq 54$ years and $>54$ years), had no substantial effects on these risk estimates. However, using the residual method for total energy intake adjustment strongly reduced the very high RR observed in the second tertile of intake of total monounsaturated fatty acids and of oleic acid.

In Table 4 we report overall total energy intake and the intake of factors found to be associated with disease risk: PUFA, linoleic acid and soluble carbohydrates. We detected in patients a tendency towards a lower intake of soluble carbohydrates and a higher intake of PUFA and linoleic acid, despite the lower intake of energy particularly in females. When we analysed the possible association of age with these factors, inverse relationships emerged in referents, whilst in patients the only association we detected was the inverse one between age and soluble carbohydrates intake (Table 5).

Table 3 Gender-specific risk* of melanoma according to daily intake of selected dietary factors, case-control study on environmental determinants of cutaneous melanoma, Modena Province, northern Italy

\begin{tabular}{|c|c|c|c|}
\hline \multirow[b]{2}{*}{ Factor } & \multicolumn{2}{|r|}{ Category } & \multirow{2}{*}{$\begin{array}{l}P \text { for linea } \\
\text { trend }\end{array}$} \\
\hline & I† & II & \\
\hline \multicolumn{4}{|l|}{ Males } \\
\hline \multicolumn{4}{|l|}{ Linoleic acid } \\
\hline Crude & 1.00 & $1.67(0.40-6.97)$ & 0.391 \\
\hline Adjusted for energy & 1.00 & $2.24(0.42-12.05)$ & 0.300 \\
\hline Adjusted for energy and soluble carbohydrates & 1.00 & $2.01(0.36-11.21)$ & 0.421 \\
\hline Adjusted for soluble carbohydrates & 1.00 & $1.89(0.43-8.27)$ & 0.388 \\
\hline Cut-off $(\mathrm{g})$ & $<7.47$ & $\geq 7.47$ & \\
\hline \multicolumn{4}{|l|}{ Soluble carbohydrates } \\
\hline Crude & 1.00 & $0.67(0.24-1.87)$ & 0.242 \\
\hline Adjusted for energy & 1.00 & $0.64(0.20-2.06)$ & 0.231 \\
\hline Adjusted for energy and linoleic acid & 1.00 & $0.70(0.22-2.30)$ & 0.314 \\
\hline Adjusted for linoleic acid & 1.00 & $0.65(0.22-1.85)$ & 0.243 \\
\hline Cut-off $(\mathrm{g})$ & $<95.53$ & $\geq 95.53$ & \\
\hline \multicolumn{4}{|l|}{ Females } \\
\hline \multicolumn{4}{|l|}{ Linoleic acid } \\
\hline Crude & 1.00 & $0.88(0.32-2.41)$ & 0.506 \\
\hline Adjusted for energy & 1.00 & $1.24(0.31-4.93)$ & 0.077 \\
\hline Adjusted for energy and soluble carbohydrates & 1.00 & $1.34(0.31-5.76)$ & 0.071 \\
\hline Adjusted for soluble carbohydrates & 1.00 & $1.73(0.47-6.39)$ & 0.046 \\
\hline Cut-off $(\mathrm{g})$ & $<7.62$ & $\geq 7.62$ & \\
\hline \multicolumn{4}{|l|}{ Soluble carbohydrates } \\
\hline Crude & 1.00 & $0.30(0.08-1.09)$ & 0.132 \\
\hline Adjusted for energy & 1.00 & $0.19(0.03-1.10)$ & 0.096 \\
\hline Adjusted for energy and linoleic acid & 1.00 & $0.14(0.02-1.02)$ & 0.077 \\
\hline Adjusted for linoleic acid & 1.00 & $0.10(0.02-0.65)$ & 0.023 \\
\hline Cut-off (g) & $<103.91$ & $\geq 103.91$ & \\
\hline
\end{tabular}

* Relative risk of melanoma (95\% confidence interval) comparing subjects with average intake greater than the cut-off value versus remaining subjects.

†Referent category (average nutrient intake below the median as calculated in controls). 
Table 4 Mean daily intake ( \pm standard deviation) of selected dietary factors in population referents and in patients with cutaneous melanoma, Modena Province, northern Italy

\begin{tabular}{lrr}
\hline Dietary factor & Females $(n=62)$ & Males $(n=56)$ \\
\hline Total polyunsaturated fatty acids $\left(\mathrm{g} \mathrm{day}^{-1}\right)$ & \\
$\quad$ Referents & $9.43 \pm 3.30$ & $9.84 \pm 3.39$ \\
$\quad$ Patients & $9.94 \pm 3.84$ & $10.52 \pm 3.68$ \\
Linoleic acid $\left(\mathrm{g} \mathrm{day}^{-1}\right)$ & & \\
$\quad$ Referents & $7.59 \pm 2.66$ & $8.00 \pm 2.91$ \\
$\quad$ Patients & $8.20 \pm 3.52$ & $8.73 \pm 3.36$ \\
Soluble carbohydrates $\left(\mathrm{g} \mathrm{day}^{-1}\right)$ & $112.19 \pm 56.29$ & $97.54 \pm 40.27$ \\
$\quad$ Referents & $95.84 \pm 24.73$ & $86.25 \pm 27.26$ \\
$\quad$ Patients & $2014.4 \pm 758.6$ & $2228.8 \pm 720.4$ \\
Total energy intake $\left(\mathrm{kcal} \mathrm{day}^{-1}\right)$ & $2195.6 \pm 518.7$ \\
$\quad$ Referents & $1893.4 \pm 501.2$ & \\
Patients & & \\
\hline
\end{tabular}

\section{Discussion}

Mackie originally reported in 1974 an unusually high incidence of melanoma (of the leg) in subjects who had partially replaced their intake of saturated fat with PUFA ${ }^{12}$. In subsequent studies, this investigator and co-workers reported higher dietary intakes and tissue levels of PUFA and, in particular, of linoleic acid - in melanoma patients compared with referents ${ }^{13-15}$. These observations fuelled a strong debate about the possible aetiological role of unsaturated fats ${ }^{16,17}$ and have also prompted a few epidemiological investigations. The first studies yielded no evidence of association between PUFA intake and melanoma risk $^{18-21}$ or even an inverse relationship ${ }^{22}$. However, a subsequent prospective investigation by Veierod et al. from Norway yielded strong evidence of a direct association between PUFA intake and subsequent melanoma occurrence ${ }^{23}$, although such a relationship was detected in females only, consistent with our results. A recent large case-control study from the USA also found a direct relationship between energy-adjusted linoleic acid intake and melanoma risk ${ }^{4}$, but that investigation differed from the present one in being hospital-based and using a so-called 'brief' food-frequency questionnaire, based on 60 items $^{24}$.

The different results obtained in the epidemiological studies published so far may be ascribed to methodological reasons, such as methodological limitations of some of the food-frequency questionnaires adopted, or to actual differences in the role of dietary risk factors across different populations. In the present study, we used a validated semi-quantitative food-frequency questionnaire specifically developed for a northern Italy population, designed to analyse consumption of a very large number of foods and important details such as cooking methods and type of fat used as condiment before and after cooking.

In this investigation, the intake of linoleic acid (and, in part, of soluble carbohydrates) was associated with melanoma risk in the multivariate analysis, i.e. when adjusting for energy and/or for the other dietary factor, but not in the bivariate one. This seems to suggest that relative excess or deficiency of these dietary variables is of considerable importance, more than their absolute intakes, in enhancing melanoma risk.

There is suggestive biological and some epidemiological evidence indicating that PUFA and more specifically linoleic acid may increase cancer occurrence at some sites, such as the breast, colon and prostate ${ }^{25-29}$, thus yielding concern about potential adverse effects of 'high' linoleic acid intake ${ }^{30,31}$. Animal studies have also indicated that unsaturated lipids enhance ultraviolet-induced carcinogenesis $^{32-34}$, adding biological plausibility to a possible relationship between PUFA intake and melanoma aetiology. A recent laboratory study in epidermal reconstructs suggests that, following ultraviolet irradiation, omega- 6 PUFA such as linoleic acid and arachidonic acid increase oxidative damage in melanocytes without inducing apoptosis, thus possibly increasing melanoma risk ${ }^{35}$.

An unanticipated finding of the present study was the indication that a higher intake of soluble carbohydrates may decrease melanoma risk. This possible effect emerged independently from adjustment for overall energy intake, and it appeared to occur in both males and females, although the statistical association was considerably stronger in females. As far as we know, there are no prior studies which have analysed in detail the association between intake of specific carbohydrates and melanoma risk, thus hampering the evaluation of our results. In a recent hospital-based case-referent study, however, energy-adjusted intake of total carbohydrates correlated inversely with melanoma risk ${ }^{4}$. In our study population, intake of soluble carbohydrates is expected to be due

Table 5 Correlation between age and selected dietary factors in population referents and in patients with cutaneous melanoma, Modena Province, northern Italy. Data expressed as Spearman correlation coefficient ( $P$-value)

\begin{tabular}{|c|c|c|}
\hline & \multicolumn{2}{|c|}{ Age } \\
\hline & $\begin{array}{l}\text { Referents } \\
(n=59)\end{array}$ & $\begin{array}{l}\text { Patients } \\
(n=59)\end{array}$ \\
\hline $\begin{array}{l}\text { Total polyunsaturated fatty acids }\left(\mathrm{g} \mathrm{day}^{-1}\right) \\
\text { Linoleic acid }\left(\mathrm{g} \mathrm{day}^{-1}\right) \\
\text { Soluble carbohydrates }\left(\text { g day }^{-1}\right) \\
\text { Total energy intake }\left(\mathrm{kcal} \mathrm{day}^{-1}\right)\end{array}$ & $\begin{array}{l}-0.299(0.022) \\
-0.253(0.053) \\
-0.233(0.076) \\
-0.292(0.025)\end{array}$ & $\begin{array}{r}-0.023(0.866) \\
0.010(0.938) \\
-0.254(0.053) \\
-0.144(0.275)\end{array}$ \\
\hline
\end{tabular}


mainly to the consumption of fruit, milk, sugar and sweets, suggesting the opportunity to further investigate a potential beneficial effect of fruit and milk intake, in particular. Recall bias does not appear to explain this association, as is also true for linoleic acid, since there is no awareness in the general population of a potential relationship of these (and other) dietary factors with melanoma risk.

The associations of linoleic acid and soluble carbohydrates with disease risk we detected were statistically more stable among females than in males. This might be due to a gender-specific effect of dietary factors in influencing melanoma risk, to an effect of unmeasured confounders or, we speculate, to a more accurate compilation of the questionnaire by the female group, with consequent beneficial effects on exposure classification and statistical precision of the point estimates.

Our results do not support sparse observations from epidemiology suggesting a relationship between melanoma and a higher intake of alcohol ${ }^{4,18,20,22}$ and vitamin $\mathrm{C}^{36}$ or with a lower intake of vitamins $\mathrm{A}^{5}, \mathrm{D}^{4}$ and $\mathrm{E}^{21,22}$, zinc $^{21,22}$, retinol $^{36}, \beta$-carotene ${ }^{4,22}$ and iron ${ }^{20,22}$. However, the epidemiology literature about these associations has generally been inconsistent, such as in the case of alcohol consumption, which has also been inversely related to melanoma risk ${ }^{19,37}$, and most studies have been unable to identify associations between the above-mentioned dietary factors and melanoma risk ${ }^{3}$.

Two important limitations of the present study must be outlined. First, the point estimates we calculated have reduced statistical precision, mainly due to the small study size: such instability of the risk estimates suggests caution in evaluating the findings of the present investigation, which need to be confirmed in larger populations. Furthermore, we cannot entirely rule out that the associations we detected might only be simple correlates of other true aetiological factors, such as dietary constituents that could not be analysed in the present study. However, we consider this hypothesis unlikely, due to the completeness of the food-frequency questionnaire and its consequent suitability to report extensively on the usual intake of dietary factors.

\section{Acknowledgements}

The authors are grateful to all the patients and referents who participated in the study, and to Giuliano Carrozzi, epidemiologist of the National Health Service Modena Unit, for providing the database of Modena residents. The authors acknowledge the co-operation in data analysis and manuscript review of Kenneth $\mathrm{J}$ Rothman of Boston University School of Public Health and of Annibale Biggeri of University of Florence School of Medicine. This study was supported by the 'Angela Serra Association for Cancer Research' of Modena and by the Italian Ministry of the
University and of the Scientific and Technological Research (grant no. 2002063519_001).

Conflicts of interest: None declared.

\section{References}

1 Ferriman A. Large increases occur in cancers of skin and prostate. British Medical Journal 2003; 327: 1306.

2 de Vries E, Bray FI, Coebergh JW, Parkin DM. Changing epidemiology of malignant cutaneous melanoma in Europe 1953-1997: rising trends in incidence and mortality but recent stabilizations in western Europe and decreases in Scandinavia. International Journal of Cancer 2003; 107: 119-26.

3 Desmond RA, Soong SJ. Epidemiology of malignant melanoma. Surgical Clinics of North America 2003; 83: $1-29$.

4 Millen AE, Tucker MA, Hartge P, Halpern A, Elder DE, Guerry D 4th, et al. Diet and melanoma in a case-control study. Cancer Epidemiology, Biomarkers \& Prevention 2004; 13: $1042-51$.

5 Naldi L, Gallus S, Tavani A, Imberti GL, La Vecchia C. Oncology Study Group of the Italian Group for Epidemiologic Research in Dermatology. Risk of melanoma and vitamin A, coffee and alcohol: a case-control study from Italy. European Journal of Cancer Prevention 2004; 13: 503-8.

6 Le Marchand L. Dietary factors in the etiology of melanoma. Clinics in Dermatology 1992; 10: 79-82.

7 Vinceti M, Bassissi S, Malagoli C, Pellecani G, Alber D, Bergomi $\mathrm{M}$, et al. Environmental exposure to trace elements and risk of cutaneous melanoma. Journal of Exposure Analysis and Enivornmental Epidemiology 2005; 15: 458-62.

8 Pisani P, Faggiano F, Krogh V, Palli D, Vineis P, Berrino F. Relative validity and reproducibility of a food frequency dietary questionnaire for use in the Italian EPIC centres. International Journal of Epidemiology 1997; 26(Suppl. 1): S152-60.

9 Pala V, Sieri C, Palli D, Salvini S, Berrino F, Bellegotti M, et al. Diet in the Italian EPIC cohorts: presentation of data and methodological issues. Tumori 2003; 89: 594-607.

10 Salvini S, Parpinel M, Gnagnarella P, Maisonneuve P, Turrini A. Banca dati di composizione degli alimenti per studi epidemiologici in Italia. Milan: Istituto Europeo di Oncologia, 1998.

11 Willett WC, Howe GR, Kushi LH. Adjustment for total energy intake in epidemiologic studies. American Journal of Clinical Nutrition 1997; 65: 1220S-8S.

12 Mackie BS. Malignant melanoma and diet. Medical Journal of Australia 1974; 1: 810.

13 Mackie BS, Johnson AR, Mackie LE, Fogerty AC, Ferris M, Baxter RI. Dietary polyunsaturated fats and malignant melanoma. Medical Journal of Australia 1980; 1: 159-63.

14 Mackie BS, Mackie LE, Curtin LD, Bourne DJ. Melanoma and dietary lipids. Nutrition and Cancer 1987; 9: 219-26.

15 Mackie BS, Mackie LE. Cancer and dietary lipids. New Zealand Medical Journal 1991; 104: 322.

16 Simpson LO. Melanoma and fatty acids. New Zealand Medical Journal 1990; 103: 569.

17 Holborow P. Melanoma and polyunsaturated fat; cancer and diet. New Zealand Medical Journal 1990; 103: 515-6.

18 Holman CD, Armstrong BK, Heenan PJ, Blackwell JB, Cumming FJ, English DR, et al. The causes of malignant melanoma: results from the West Australian Lions Melanoma Research Project. Recent Results in Cancer Research 1986; 102: $18-37$.

19 Osterlind A, Tucker MA, Stone BJ, Jensen OM. The Danish case-control study of cutaneous malignant melanoma. IV. 
No association with nutritional factors, alcohol, smoking or hair dyes. International Journal of Cancer 1988; 42: 825-8.

20 Stryker WS, Stampfer MJ, Stein EA, Kaplan L, Louis TA, Sober A, et al. Diet, plasma levels of $\beta$-carotene and $\alpha$-tocopherol, and risk of malignant melanoma. American Journal of Epidemiology 1990; 131: 597-611.

21 Kirkpatrick CS, White E, Lee JA. Case-control study of malignant melanoma in Washington State. II. Diet, alcohol, and obesity. American Journal of Epidemiology 1994; 139: 869-80.

22 Bain C, Green A, Siskind V, Alexander J, Harvey P. Diet and melanoma. An exploratory case-control study. Annals of Epidemiology 1993; 3: 235-8.

23 Veierod MB, Thelle DS, Laake P. Diet and risk of cutaneous malignant melanoma: a prospective study of 50,757 Norwegian men and women. International Journal of Cancer 1997; 71: 600-4.

24 Block G, Hartman AM, Naughton D. A reduced dietary questionnaire: development and validation. Epidemiology 1990; 1: 58-64.

25 Rose DP. Dietary fat, fatty acids and breast cancer. Breast Cancer 1997; 4: 7-16.

26 Zock PL, Katan MB. Linoleic acid intake and cancer risk: a review and meta-analysis. American Journal of Clinical Nutrition 1998; 68: 142-53.

27 Bartsch H, Nair J, Owen RW. Dietary polyunsaturated fatty acids and cancers of the breast and colorectum: emerging evidence for their role as risk modifiers. Carcinogenesis 1999; 20: 2209-18.

28 Newcomer LM, King IB, Wicklund KG, Stanford JL. The association of fatty acids with prostate cancer risk. Prostate 2001; 47: 262-8.
29 Astorg P. Dietary $n-6$ and $n-3$ polyunsaturated fatty acids and prostate cancer risk: a review of epidemiological and experimental evidence. Cancer Causes \& Control 2004; 15 367-86.

30 Erickson KL. Is there a relation between dietary linoleic acid and cancer of the breast, colon, or prostate? American Journal of Clinical Nutrition 1998; 68: 5-7.

31 Hamazaki T, Okuyama H. The Japan Society for Lipid Nutrition recommends to reduce the intake of linoleic acid. A review and critique of the scientific evidence. World Review of Nutrition and Dietetics 2003; 92: 109-32.

32 Black HS, Lenger W, Phelps AW, Thornby JI. Influence of dietary lipid upon ultraviolet-light carcinogenesis. Nutrition and Cancer 1983; 5: 59-68.

33 Mathews-Roth MM, Krinsky NI. Effect of dietary fat level on UV-B induced skin tumors, and anti-tumor action of $\beta$-carotene. Photochemistryand Photobiology 1984; 40: 671-3.

34 Black HS, Thornby JI, Gerguis J, Lenger W. Influence of dietary omega- $6,-3$ fatty acid sources on the initiation and promotion stages of photocarcinogenesis. Photochemistry and Photobiology 1992; 56: 195-9.

35 Cario-Andre M, Briganti S, Picardo M, Nikaido O, de Verneuil H, Taieb A. Polyunsaturated fatty acids partially reproduce the role of melanocytes in the epidermal melanin unit. Experimental Dermatology 2005; 14: 194-201.

36 Feskanich D, Willett WC, Hunter DJ, Colditz GA. Dietary intakes of vitamins $\mathrm{A}, \mathrm{C}$, and $\mathrm{E}$ and risk of melanoma in two cohorts of women. British Journal of Cancer 2003; 88: $1381-7$.

37 Sigvardsson S, Hardell L, Przybeck TR, Cloninger R. Increased cancer risk among Swedish female alcoholics. Epidemiology 1996; 7: 140-3. 